\title{
New endemic woody plant record for Bartın: Juniperus oxycedrus f. yaltirikiana Avci \& Ziel.
}

\author{
Barbaros YAMAN ${ }^{*}$, Zafer KAYA ${ }^{1}$ and Halil Barış ÖZEL ${ }^{2}$ \\ ${ }^{* 1}$ Forest Botany Department, Forest Engineering Division, Faculty of Forestry, Bartın University, 74100 \\ Bartın, Turkey. \\ ${ }^{2}$ Silviculture Department, Forest Engineering Division, Faculty of Forestry, Bartın University, 74100 Bartın, \\ Turkey. \\ Corresponding author: yamanbar@gmail.com
}

\begin{abstract}
The endemic juniper form of Turkey, Juniperus oxycedrus f. yaltirikiana Avci \& Ziel., was first described by Avc1 and Zielinski in 2008. The locality of its holotype is between Göbü and Türkali in Northeast of Zonguldak. According to our current knowledge, another distribution locality of this juniper form is unknown except the holotype locality. The present study is related to the new distribution area of this endemic juniper and its vegetation structure and sociological properties.
\end{abstract}

Key Words: Juniper, endemic, new record, Bartin

\section{Özet}

Makalede adı geçen Türkiye'nin endemik ardıç formu (Juniperus oxycedrus f. yaltirikiana Avci \& Ziel.) ilk kez Avcı ve Zielinski tarafından 2008 yılında tanımlanarak bilim dünyasına sunulmuştur. Bu taksonun ilk tip örneklerinin alındığı ve tanımlandığı lokalite Zonguldak ilinin kuzey-doğusunda Göbü ve Türkali köyleri arasındaki bölgede bulunmaktadır. Bugünkü bilgilerimize göre, bu ardıç formunun ilk tanımlandığı lokalite dışında yayılış yaptığı başka bir yayılış alanı bilinmemektedir. Makalede söz konusu endemik ardıç formunun morfolojik özellikleri ve oldukça sınırlı bir alandaki yeni yayılışı konu edilerek, alanın vejetasyon tipi ve bitki toplumları açısından kısa bir tanıtımı yapılmıştır.

Anahtar Kelimeler: Ardıç, endemik, yeni kayıt, Bartın

\section{Giriş}

Makalede adı geçen endemik ardıç formu (Juniperus oxycedrus f. yaltirikiana Avci \& Ziel.) ilk kez Avcı ve Zielinski (2008) tarafından tanımlanarak bilim dünyasına sunulmuştur. Bu taksonun ilk tip örneklerinin alındığı ve tanımlandığg lokalite Zonguldak ilinin kuzey-doğusunda Göbü ve Türkali köyleri arasındaki bölgede bulunmaktadır. Bugünkü bilgilerimize göre, bu ardıç formunun ilk tanımlandığı lokalite dışında yayılış yaptığı başka bir yayılış alanı bilinmemektedir. Ancak, Bartın ilinin karasal ve iç su ekosistemleri biyoçeşitlilik envanter ve izleme çalışmaları kapsamında 2016-17 vejetasyon dönemlerinde gerçekleştirilen arazi çalışmaları esnasında bu endemik taksonun Bartın il sınırları içerisinde de habitatının bulunduğu ilk kez tespit edilmiştir. Makalede söz konusu endemik ardıç formunun (J. oxycedrus f. yaltirikiana Avci \& Ziel.) morfolojik özellikleri ve oldukça sınırlı bir alandaki yeni yayılışı konu edilerek, alanın vejetasyon tipi ve bitki toplumları açısından kısa bir tanıtımı yapılmıştır. 


\section{Materyal ve Yöntem}

Bartın ilinin karasal ve iç su ekosistemleri biyoçeşitlilik envanter ve izleme çalışmaları kapsamında 2016 ve 2017 yılları vejetasyon döneminde Bartın ili sınırları içerisinde bulunan bütün paftalara gidilerek gözlem yapılmış, bitki örnekleri toplanmış ve in-situ fotoğrafları çekilmiştir. Bitki örnekleri toplama sürecinde Davis (1962)'de belirtilen kurallara uyulmuştur. Kurutulan bitki örnekleri Bartın Üniversitesi Orman Fakültesi Herbaryumu'nda saklanmaktadır.

\section{Bulgular}

\section{Juniperus oxycedrus L. f. yaltirikiana Avci \& Ziel.’nın Habitatı}

Juniperus oxycedrus f. yaltirikiana Avci \& Ziel. Bartın ilinin batısında Bartın - Zonguldak il sınırına yakın bir konumda bulunan Hatipler sahil bölgesinde 10-15 bireyden oluşan bir topluluk olarak bulunmaktadır. Türün yeni habitatı $41^{\circ} 35^{\prime} 45.88^{\prime \prime}$ kuzey enlemi ile $32^{\circ} 08^{\prime} 09.75^{\prime \prime}$ doğu boylamının kesiştiği noktada yer almaktadır (Şekil 1). Ortalama rakımı ise 10 m'dir. Bu noktanın türün ilk tip örneğinin tespit edildiği Zonguldak ilinin kuzey-doğusundaki Göbü ve Türkali köyleri arasındaki bölgeye olan kuş uçuşu uzaklığg yaklaşık 16 km'dir.

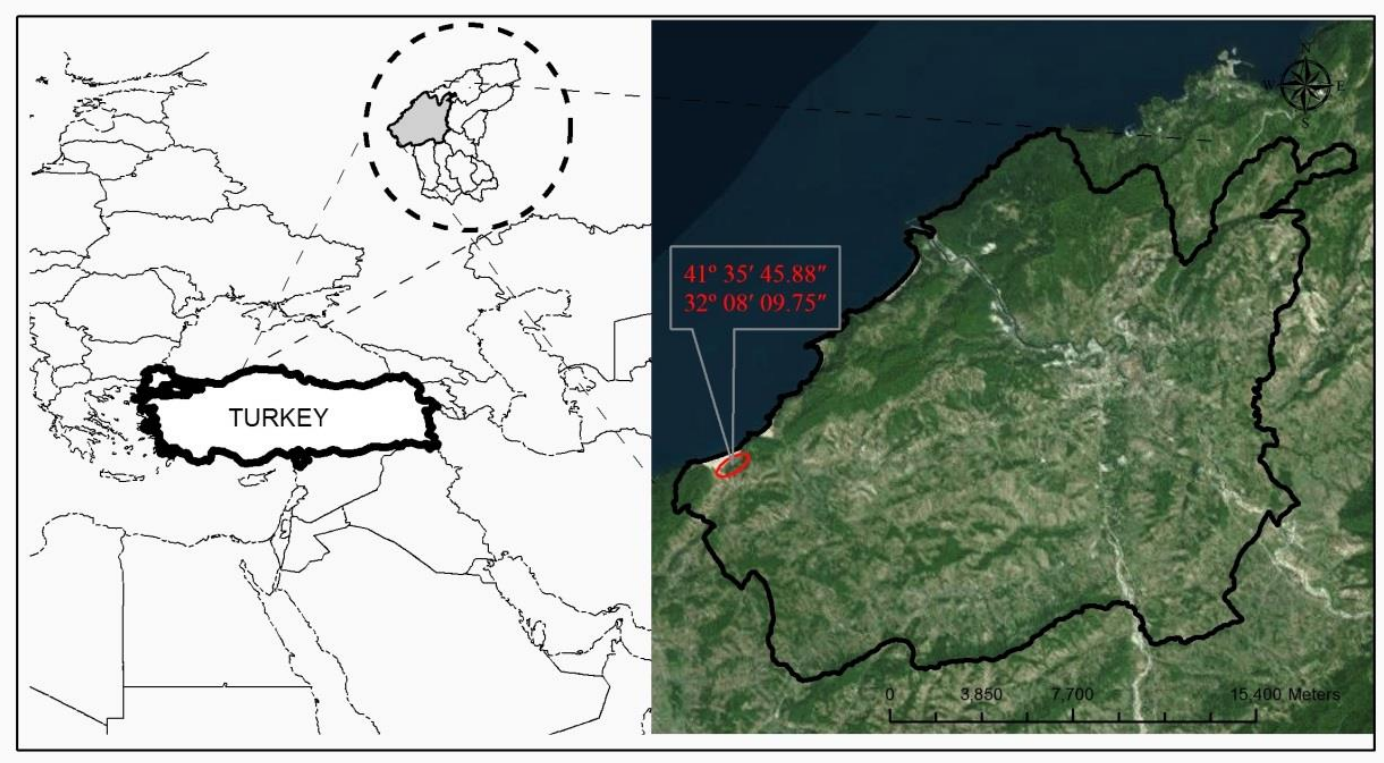

Şekil 1. Juniperus oxycedrus f. yaltirikiana Avci \& Ziel'in Bartın ilindeki doğal yayılış alanı.

Forma yaltirikiana'nın bulunduğu yeni habitat deniz kıyısına $450 \mathrm{~m}$. mesafede, kumul ardı ve deniz etkisine açık bir konumdadır. Alan içerisinde yer alan orman vejetasyonu yapısı incelendiğinde; ara ve alt tabakada bulunan çalı katında genel olarak Laurus nobilis L, Phillyrea latifolia L., Juniperus oxycedrus L. subsp. oxycedrus türleri yer almakta olup, ağaç katında doğal ve yapay olarak alana gelmiş bulunan ağaç türü varyantları yer almaktadır. Buna göre doğal olarak alanda bulunan ağaç katı elemanlarını Quercus petraea subsp. petraea (Matt.) Liebl., Carpinus betulus L. ve Fagus orientalis Lipsky. oluşturmaktadır. Ağaç katının yapay olarak alanda yer alan elemanlarını ise Pinus pinea L. ve Pinus pinaster Aiton meydana getirmektedir. Araştırma alanındaki orman vejetasyon yapısı genel olarak tek tabakalı ve aynı yaşı kuruluşa sahip karışık orman formasyonundadır. Yukarıda belirtilen fistıkçamı ve sahil çamı şeklindeki iğne yapraklı türler karışıma genel olarak münferit ya da küme karışım şeklinde dahil olmaktadırlar. Bunun yanı sıra alanda meşcere parametreleri yönünden yüksek ışı entansitesinin bulunduğu 1ş1klı kapalılık durumu hâkim olup, yan ve ana sırtlarda bulunan orman kuşaklarında kapalılık genel olarak 0,5-0,7 arasında değişmektedir. Bununla birlikte kumul vejetasyonuna giren ve orman kenarı niteliğindeki bu alanda hem forma yaltirikiana'ya hem de ağaç katındaki tüm elemanlara 
ara ve alt tabakada yoğun olarak defnenin eşlik ettiği görülmektedir. Bununla birlikte araştırma alanı orman zonları açısından, genel olarak Lauretum zonunda yer almakta olup, yer yer deniz ardında yer alan yükselti kuşaklarında Castanetum zonuna geçişler söz konusudur. Forma yaltirikiana'nın tespit edildiği araştırma alanı bitki sosyolojisi açısından incelendiğinde ise genel olarak Öksin Bitki Kuşağının içinde yer almakta olup, aşağıdaki gibi isimlendirilen özel bitki topluluğuna dahil olmaktadır;

Quercetea ilicis Braun-Blanquet ex A. \& O. Bolòs 1950

Quercetalia ilicis Br.-Bl. ex Molinier 1934

Quercion ilicis Br.-Bl. exMolinier 1934

Lauro-Pinetum brutiae Yurdakulol vd. 2002.

\section{Tartışma ve Sonuç}

Katran Ardıcı(Juniperus oxycedrus L.)'nın 4 farklı alttürü bulunmaktadır. Bu alt türler; Juniperus oxycedrus subsp. oxycedrus, subsp. badia, subsp. macrocarpa ve subsp. transtagana'dır (Farjon 2005 ve 2010). Bunlardan Juniperus oxycedrus subsp. oxycedrus Türkiye'de doğal olarak yetişmektedir (Yılmaz ve ark. 2011). Gövdenin dip kısımlarından itibaren dar açı ile yukarıya doğru yönelen sık dalları ile 2,5-3,5 m boyunda iğ biçiminde - sütun şeklinde bir habitusa sahip olan Katran Ardıcının bir formu Avc1 ve Zielinski (2008) tarafından $J$. oxycedrus L. forma yaltirikiana olarak isimlendirilmiş ve taksonomik konumu ile ilgili aşağıdaki bilgiler verilmiştir:

Juniperus oxycedrus L., Sp. Pl. 1038 (1753)

subsp. oxycedrus

var. oxycedrus

f. yaltirikiana Meral Avci \& Ziel.

var. spilinanus Yalt., Eliçin \& Terzioğlu, Turk. J. Bot. $31: 38$ (2007)

subsp. transtagana Franco, Feddes Repert. 68: 166 (1963)

subsp. badia (H. Gay) Debeaux, Fl. Kabylie: 411 (1894)

Adams (2008) ise Katran Ardıcını J. oxycedrus var. oxycedrus ve var. badia olmak üzere iki varyete olarak değerlendirmiştir. Bu değerlendirmeye göre, J. oxycedrus subsp. oxycedrus'un Batı Akdeniz (İtalya'dan batıya doğru) yayılışındaki bireyleri var. oxycedrus olarak kabul edilirken, Doğu Akdeniz (İtalya'dan doğuya doğru) yayılışındaki bireyleri ise Juniperus deltoides R. P. Adams olarak yeniden isimlendirilmiştir. Bu bağlamda Adams ve Mataracı (2011) nükleer ribozomal DNA ve petN-psbM analizlerine dayanarak; Avcı ve Zielinski (2008) tarafından forma yaltirikiana olarak isimlendirilen bu ardıç formunu taksonomik olarak Juniperus deltoides R. P. Adams'ın altında konumlandırmıştır. Bir başka söyleyişle; Juniperus oxycedrus L. forma yaltirikiana Avci \& Ziel., Juniperus deltoides R. P. Adams forma yaltirikiana (M. Avci \& Ziel.) R. P. Adams'nın basionimi olmuştur (IPNI 2018). Ancak koniferlerle ilgili yapılan bazı yayınlarda Türkiye'deki J. oxycedrus subsp. oxycedrus popülasyonlarına J. deltoides demenin mümkün olmadığı belirtilmektedir (Klimko ve diğ. 2007, Yılmaz ve diğ. 2011, Fakir 2018). Ayrıca Gymnospermae veri tabanında ardıçlarla ilgili taksonomik notlarda dünyada kabul edilen 55 ardıç türü arasında J. deltoides'e yer verilmediği görülmektedir (The Gymnospermae Database 2018). Diğer taraftan Kandemir (2018) Resimli Türkiye Florası-2'de katran ardıcının yaltirikiana formunu Juniperus oxycedrus L. subsp. oxycedrus'un sinonimi olarak göstermiştir.

Katran ardıcı, çok farklı habitatlara uyum sağlaması nedeniyle, taç görünümü, dallanma ve yaprak özellikleri bakımından geniş varyasyon gösteren bir taksondur. Bu nedenle iğ biçiminde - sütun şeklinde 
bir habitusa sahip olan katran ardıcı yaltirikiana formunun Zonguldak Göbü-Türkali ve Bartın Hatipler Köyü sahilindeki popülasyonlarının daha ayrıntılı çalışılması gerekir. Bu durumda yeni taksonomik veriler elde edilene kadar Katran Ardıcının iğ biçiminde - sütun şeklindeki bu formu için Juniperus oxycedrus f. yaltirikiana Avci \& Ziel. şeklindeki taksonomik isimlendirmeyi kullanmak kanımızca yerinde olacaktır. Aynı zamanda iğ biçiminde - sütun şeklindeki habitusu nedeniyle peyzaj açısından süs bitkisi potansiyeli taşıyan katran ardıcı yaltirikiana formunun geleceğe ulaşabilmesi için in-situ ve ex-situ olarak korunması önem arz etmektedir.
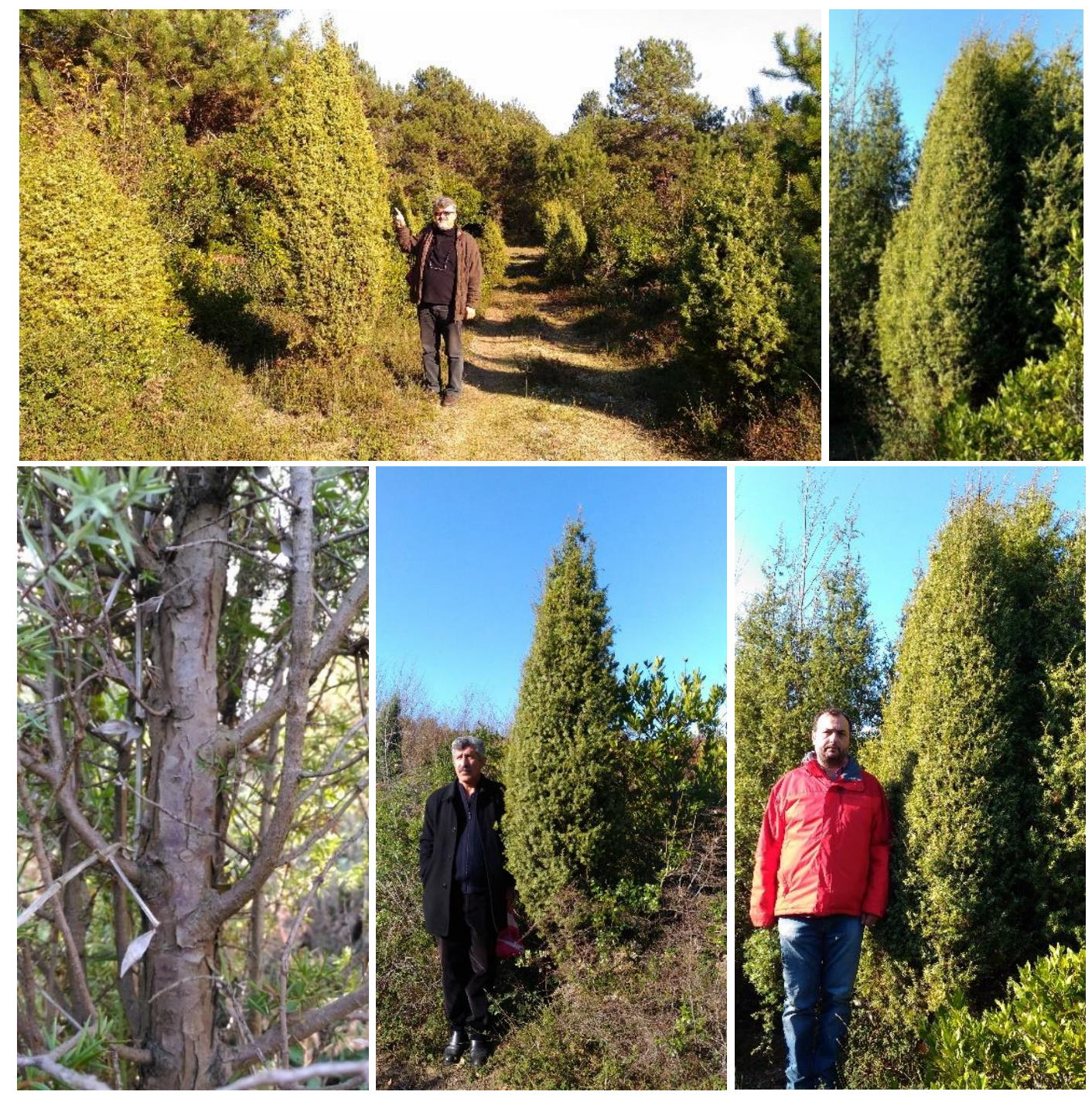

Şekil 2. Juniperus oxycedrus f. yaltirikiana'nın habitat ve habitusu ile ilgili genel görünüm.

\section{Teşekkürler}

Doğa Koruma ve Milli Parklar Genel Müdürlüğü-10. Bölge Müdürlüğü’ne bağl1 Bartın Şube Müdürlüğü görevlileri ile Çınar Mühendislik çalışanlarına arazi çalışmalarımız sırasında gösterdikleri ilgi ve yardım nedeniyle teşekkür ederiz.

\section{Kaynaklar}

Adams, R.P. (2008) Junipers of the world: the genus Juniperus, $2^{\text {nd }}$ edition. Trafford Publishing Co., Vancouver, Canada, 402 pp.

Adams R.P. \& Matarac1 T. (2011) Taxonomy of Juniperus deltoldes forma Yaltirikiana in Turkey: Leaf Terpenords and SNPs from nrDNA and petN. Phytologia 93: 293-303. 
Avcı M.. \& Zielinski J (2008) Juniperus oxycedrus f. yaltirikiana (Cupressaceae): a new form from NW Turkey. Phytologia Balcanica 14(1): 37-40.

Braun-Blanquet, J. (1932). Plant sociology, New York.

Davis P.H. (1962) Bitki Toplayıcılarına Tavsiyeler. Çeviri: F. Yaltırık, İ.Ü. Orman Fakültesi Dergisi, Seri B, 12(2): 121-126.

Fakir H. (2018) Juniperus L. (Ardıçlar). Türkiye’nin Doğal Egzotik Ağaç ve Çalıları I (ed. Ü. Akkemik), Orman Genel Müdürlüğü Yayınları, Ankara, s. 79-84.

Farjon A. (2005) A monograph of Cupressaceae and Sciadopitys. Royal Botanic Gardens, Kew.

Farjon, A. (2010) A Handbook of the World's Conifers. Vol.1, Koninklijke Brill NV, Leiden-Boston.

IPNI (2018) The International Plant Name Index. www.ipni.org (30.03.2018).

Kandemir A. (2018) Juniperus L., Resimli Türkiye Florası-2 (ed. A. Güner), ANG Vakfı Nezahat Gökyiğit Botanik Bahçesi, İstanbul.

Klimko M., Boratyńska A., Monserrat J., Didukh Y., Romo A., Gomez D., Kluza-Wieloch M., Marcysiak K. \& Boratyński A. (2007). Morphological variation of Juniperus oxycedrus subsp. oxycedrus (Cupressaceae) in the Mediterranean region. Flora, 202: 133-147.

The Gymnospermae Database (2018) Juniperus L. www.conifers.org (30.03.2018).

Yılmaz H., Aksoy N., Akkemik Ü., Köse N., Karlığlu N. \& Kaya A. (2011) Cupressaceae: Juniperus L. Türkiye'nin Doğal Gymnospermleri (Açık Tohumlular) (eds. F. Yaltırık \& Ü. Akkemik), T.C. Orman ve Çevre Bakanlı̆̆ı, Orman Genel Müdürlüğü, Ankara, s.121-171.

Yurdakulol, E., Demirörs, M., Yıldız, A. (2002). A phytosociological study of the vegetation of the Devrekaniİnebolu-Abana area (Kastamonu, Turkey), Israel Journal of Plant Sciences, 50: 293-311.

Submitted: 10.04.2018

Accepted: 18.05.2018 